\title{
Attenuating fibrotic markers of patient-derived dermal fibroblasts by thiolated lignin com- posites
}

Jorge A. Belgodere ${ }^{1, \$}$, Dongwan Son ${ }^{2, \$}$, Bokyoung Jeon ${ }^{1,2,}$, Jongwon Choe ${ }^{1,2}$, Anna C. Guidry ${ }^{1}$, Adam X. Bao ${ }^{1}$, Syed A. Zamin ${ }^{1}$, Umang M. Parikh ${ }^{3}$, Swathi Balaji ${ }^{3}$, Myungwoong Kim ${ }^{2 *}$, Jangwook P. Jung ${ }^{1 *}$

${ }^{1}$ Department of Biological Engineering, Louisiana State University, Baton Rouge, LA

${ }^{2}$ Department of Chemistry and Chemical Engineering, Inha University, Incheon 22212, Republic of Korea

${ }^{3}$ Department of Surgery, Texas Children's Hospital and Baylor College of Medicine, Houston, TX ${ }^{\$}$ co-first author

${ }^{*}$ Corresponding authors:

Jangwook P. Jung, Ph.D.

Department of Biological Engineering

Louisiana State University

167 E.B. Doran Hall

Baton Rouge, LA 70803

Phone: (225) 578-2919

Fax: (225) 578-3492

E-mail: jung1@|su.edu

Myungwoong Kim, Ph.D.

Department of Chemistry and Chemical Engineering

Inha University

Incheon 22212, Republic of Korea

Phone: +82-32-860-7680

Fax:+82-32-860-9246

E-mail: mkim233@inha.ac.kr 


\section{ABSTRACT}

Engineering composite biomaterials requires the successful integration of multiple feedstocks to formulate a final product for functional improvement. Here we engineered biomaterial scaffolds to attenuate the fibrotic phenotype exhibited by high scarring (HS) patient-derived dermal fibroblasts (hdFBs) by valorizing lignosulfonate from waste feedstocks of lignin. We utilized phenolic functional groups of lignosulfonate to impart antioxidant properties and the cell binding domains of gelatin to enhance cell adhesion for poly(ethylene glycol)-based scaffolds. Highly efficient chemoselective thiol-ene chemistry was utilized for the formation of composites with thiolated lignosulfonate (TLS) and methacrylated fish gelatin (fGelMA) in the PEG(poly (ethylene glycol))-diacrylate matrix. Antioxidant properties of lignosulfonate was not altered after thiolation and the levels of antioxidation were comparable to a well-known antioxidant, $L$-ascorbic acid, as evidenced by DPPH (2,2-diphenyl-1-picrylhydrazyl) and TAC (Total Antioxidant Capacity) assays. Unlike porcine gelatin, fGelMA remained liquid at room temperature and exhibited low viscosities, resulting in no issues of miscibility when mixed with PEG. PEG-fGelMA-TLS composites significantly reduced the differential of five different fibrotic markers (COL1A1, ACTA2, TGFB1 and TGFB1) between HS and low scarring (LS) hdFBs, providing the potential utility of TLS in a biomaterial scaffold to attenuate fibrotic responses.

Keywords: antioxidation, fish gelatin, lignosulfonate, fibrosis, wound healing 


\section{INTRODUCTION}

Reactive oxygen species (ROS) are generated in aerobic cells either as by-products during mitochondrial electron transport or by oxidation of metabolites ${ }^{1}$. In mammalian cells, the most common and of greatest concern are superoxide anion $\left(\mathrm{O}_{2}{ }^{-}\right)$, hydrogen peroxide $\left(\mathrm{H}_{2} \mathrm{O}_{2}\right)$, and hydroxyl radicals $\left({ }^{\circ} \mathrm{OH}\right)$. Elevated levels of ROS, beyond normal physiological conditions, cause cellular damage, oxidative stress, and DNA damage. While ROS is considered toxic agents to disrupt cell division and induce apoptosis, ROS serves as signaling molecules when tightly regulated and then are taken up by the cell ${ }^{2-4}$. Low levels of ROS have been shown to stimulate cell proliferation in multiple cell types including fibroblast, macrophage, endothelial cells, and smooth muscle cells ${ }^{5-10}$. In certain cases, the reduction of intracellular ROS levels leads to the decrease in cellular proliferation and cell cycle arrest ${ }^{11-13}$. Thus, the critical balance of intracellular ROS is of vital importance for cell survival with the increase in extracellular ROS most likely leading to cellular apoptosis, unwanted intracellular signaling, and/or genotypic changes that can manifest as phenotypic changes.

Lignin is one of the most abundant naturally occurring polyphenolic organic polymers, ranging between 15 to $30 \%$ of cell wall content; while technical lignin is generated in vast quantities (approximately 45 and 2 million tons/year of kraft lignin and lignosulfonates, respectively) by the paper industry with only $\sim 2 \%$ being commercialized for dispersants, adhesives, surfactants, or as an antioxidant in plastic and rubber ${ }^{14-16}$. Due to the naturally occurring polyphenolic structures in lignin, the $\mathrm{OH}$ functional groups possess the ability to neutralize radicals, including those present at a wound site ${ }^{17-18}$. Increased interest into the antioxidant properties of lignin has spurred a line of commodity products, such as sunscreen or biocomposites, all showing promising results with very little interest into interactions with damaged tissue microenvironments. Recently, we demonstrated the incorporation of lignosulfonate into the collagen matrix resulting in enhanced mechanical properties while avoiding cytotoxic and immunogenic responses for use as in vitro 
scaffolds or in vivo tissue repairs ${ }^{19}$. To reduce the variation of biochemical and mechanical properties of lignin-based scaffolds, we attempted to utilize highly efficient, covalent crosslinking to form composites that support tissue engineering applications. Here, we employed poly(ethylene glycol) (PEG)/methacrylated fish gelatin (fGelMA) composites to assess the antioxidant capacity of lignosulfonate. Although lignosulfonate and fish gelatin have not been widely used in tissue engineering applications, their applications have been increasingly reported as a sustainable source of engineered biomaterials ${ }^{20-28}$.

Utilization of fish gelatin is advantageous, compared to mammalian gelatin, due to public health concerns (Bovine Spongiform Encephalopathy, foot-and-mouth disease, and swine influenzas), religious conflictions (Muslim and Jewish communities), and the availability/underutilization (about $50 \%-70 \%$ of freshwater processing are wasted) $)^{29-35}$. A key difference between fish and mammalian gelatins is a lower proline and hydroxyproline content resulting in a decrease in mechanical properties, altering the sol-gel transition temperature allowing fish gelatin to remain liquid at room temperature ${ }^{29-31}$. Fish gelatin exhibits excellent film-forming properties and can form mechanically stable films that survive additional processing steps ${ }^{36-37}$. Methacrylation and thiol-ene chemoselective chemistry offer a controllable crosslinking methodology to confer enhanced stiffness, while gelatin still provides integrin binding sites for tissue scaffolds ${ }^{38}$. Thus, employing both lignosulfonate and fish gelatin provides a sustainable feedstock while valorizing currently underutilized waste products.

Here, we functionalize 3-mercaptopropionic acid to lignosulfonate to form thiolated lignosulfonate (TLS) allowing conjugation of the lignosulfonate to diacrylated PEG (PEGDA) and fGelMA via thiol-ene chemistry. Thiol-ene chemistry ${ }^{39-40}$ is one of the most extensively utilized methods for high yields, experimentally straightforward methods, and having little to no byproducts $^{41-43}$. The reaction manipulates carbon-sulfur bonds that must use either base-catalyzed electron-deficient alkenes or by a radically initiated reaction with UV irradiation or thermolysis ${ }^{44-45}$. Since neither PEGDA nor TLS provide cell adhesion sites, we formed composites with fGelMA 
for cultures of patient-derived dermal fibroblasts. We characterized the functionalization, antioxidant capacity and mechanical properties of PEG-fGelMA-TLS composites and the modulation of fibrotic gene (COL1A1, ACTA2, TGFB1 and HIF1A) expression.

\section{MATERIALS AND METHODS}

$\underline{\text { Thiolation of sodium lignosulfonate }}$

To produce thiolated lignosulfonate (TLS), sodium lignosulfonate (SLS, TCI Chemicals, Cat\#L0098, Lot\#V5VJF-IC, >94\% purity) was functionalized with thiol groups by acid-catalyzed esterification (Figure 1). For thiolation, $1 \mathrm{~g}$ of SLS was dissolved in $10 \mathrm{~mL}$ of Milli-Q water in an Erlenmeyer flask, then $1 \mathrm{~mL}$ of 3-mercaptopropionic acid (TCl Chemicals, Cat\#M0061) and 0.1 $\mathrm{mL}$ of hydrochloric acid (Fisher scientific, 37\% purity, Cat\#A144S-500) were added to the solution. The flask was purged with nitrogen gas and placed in an oil bath at $80^{\circ} \mathrm{C}$. After $24 \mathrm{~h}$, the flask was removed and filled with $100 \mathrm{~mL}$ of isopropyl alcohol (IPA, VWR, Cat\#700002-608) until the TLS precipitated. The mixture was then transferred to $50 \mathrm{~mL}$ conical tubes, centrifuged at 4300 RCF for 10 min. The supernatant removed was removed and replaced with fresh IPA, which was repeated two more times. After this washing step was completed, solid TLS was separated using a Buchner funnel and vacuum dried for $24 \mathrm{~h}$.

\section{Ellman's assay for quantification of thiolation}

The degree of thiolation was determined using Ellman's assay (5,5'-dithiobis(2-nitrobenzoic acid) (Ellman's reagent, Acros Organics, 99\% purity, Cat\#AC117540010), following the manufacturer's protocol. Briefly, the reaction buffer was made by dissolving $2.130 \mathrm{~g}$ of sodium phosphate (Acros Organics, Cat\# AC204851000) and $43.5 \mathrm{mg}$ of ethylenediaminetetraacetic acid (EDTA, TCl Chemicals, Cat\# E0084) in $150 \mathrm{~mL}$ of phosphate buffer saline (PBS, Fisher Scientific, Cat\# BP399-4). In an Eppendorf tube, Ellman's reagent was dissolved in the reaction buffer to create a $4 \mathrm{mg} / \mathrm{mL}$ solution. In separate Eppendorf tubes, TLS and SLS were also dissolved in the 
reaction buffer. Using L-cysteine hydrochloride monohydrate (Alfa Aesar, 99\% purity, Cat\#A10389-14) a serial dilution was prepared to create a standard curve. In separate Eppendorf tubes, $125 \mu \mathrm{L}$ of either the standards or unknowns, $25 \mu \mathrm{L}$ of the Ellman's reagent, and $1.25 \mathrm{~mL}$ of the reaction buffer were mixed. The solutions were then pipetted into a 96-well plate and incubated at room temperature for $30 \mathrm{~min}$. Absorbance was monitored at $412 \mathrm{~nm}$ and thiol concentrations were calculated using the standard curve.

\section{Methacrylation of fish gelatin (fGelMA)}

fGelMA was prepared by the reaction of primary amine in gelatin with glycidyl methacrylate $\left(G M A\right.$, Sigma, Cat\# 151238) ${ }^{46}$. In 100 mL of DMSO (DMSO, TCI Chemicals, Cat\# D0798), $10 \mathrm{~g}$ of gelatin from cold water skin (fGel, Sigma, Cat\# G7041) was added and stirred at $50^{\circ} \mathrm{C}$ for 30 min until the fGel is fully dissolved. Then, $4 \mathrm{~mL}$ of $\mathrm{GMA}$ and $0.6 \mathrm{~g}$ of 4 -(dimethylamino)pyridine (DMAP, Alfa Aesar, Cat\# A13016) were slowly added to the fGel solution, followed by further stirring at $50^{\circ} \mathrm{C}$ for 2 days. The reaction mixture was dialyzed against $\mathrm{DI}$ water at $40^{\circ} \mathrm{C}$ using dialysis tubes (Spectra/Por 3, Spectrum ${ }^{\mathrm{TM}}$, 3500 Da molecular weight cut-off (MWCO)) for 5 days. The dialyzed fGelMA solution was lyophilized over 4 days.

\section{NMR spectroscopy of thiolation and methacrylation}

The degree of functionalization of TLS was determined using quantitative nuclear magnetic resonance (NMR) spectroscopy with ${ }^{1} \mathrm{H}$ and ${ }^{31} \mathrm{P}$ NMR (JNMECZ400S $400 \mathrm{MHz}, \mathrm{JEOL}$ ), following the literature ${ }^{47-48}$. Cyclohexanol was added as an internal standard for quantification (145.0 ppm) for ${ }^{31} \mathrm{P}$ NMR. Comparing integrated peak area of the standard to areas of aliphatic $\mathrm{OH}$ and phenolic $\mathrm{OH}$, the degree of the functionalization was determined. ${ }^{1} \mathrm{H}$ NMR spectrum of fGelMA was acquired in deuterium oxide $\left(\mathrm{D}_{2} \mathrm{O}\right.$, Cambridge Isotope Laboratories, Inc., DLM-4-25).

\section{Formation of PEG-fGelMA composite}


PEG composites were formed by weighing out PEG-diacrylate (PEGDA, Laysan bio, Cat\# ACRL-PEG-ACRL-10K-5g), lithium phenyl-2,4,6-trimethylbenzoylphosphinate (LAP, Cat\# LAP, Allevi), and TLS. The final concentrations of PEG and LAP were 40 and $5 \mathrm{mg} / \mathrm{mL}$, respectively. TLS concentration was varied based on molar ratios between the acrylate groups on the PEGDA and thiol groups on the lignin, fixed at 1:0.5 (ene:thiol). To enhance cellular adhesion, $200 \mathrm{mg} / \mathrm{mL}$ fGelMA and $5 \mathrm{mg} / \mathrm{mL}$ LAP solutions were added to the PEG solution. The optimal ratio of PEG to fGelMA was 80:20 (v/v). Solutions were pipetted into custom molds and UV crosslinked using a UV floodlamp (Intelli-Ray 400, Uvitron international) for $120 \mathrm{~s}$ at $10 \mathrm{~mW} / \mathrm{cm}^{2}$.

\section{Oscillating rheometry}

Using a TA Discovery HR-2 rheometer, viscosity was measured in a flow ramp setting (shear rate from 1 to $100(1 / \mathrm{s})$ ) and with a $25 \mathrm{~mm}$ parallel plate. Using an $8 \mathrm{~mm}$ parallel plate, storage $\left(G^{\prime}\right)$ and loss $\left(G^{\prime \prime}\right)$ moduli of composites were determined by frequency sweeping from 0.62 to $19.9(\mathrm{rad} / \mathrm{s})$ at $2 \%$ strain. In addition, instead of evaluating stiffness at an arbitrary storage modulus (often storage moduli are altered by axial stress applied during measurement), we evaluated the slope of axial stress vs compression, similar to evaluating Young's modulus from the slope of a stress-strain curve ${ }^{49}$. Axial stresses at 0,10 and $20 \%$ of compression were determined, while composite samples were subject to $2 \%$ strain and $6.28 \mathrm{rad} / \mathrm{s}$ frequency.

\section{$\underline{\text { DPPH assay }}$}

The antioxidant activity of SLS and TLS was evaluated using the 2,2-dipehnyl-1-picrylhydrazyl (DPPH, Alfa Aesar, Cat\# 44150) radical scavenging assay. Briefly, a $0.2 \mathrm{mM}$ DPPH solution was prepared in 1:1 mixture of ethanol (Fischer, Cat\# BP2818-500, 200 proof) and water (Fisher, Cat\# W2-4) since SLS or TLS is not completely soluble in ethanol. DPPH solution without sample was used as the control. After incubating samples in darkness at room temperature for 
$30 \mathrm{~min}$ and $24 \mathrm{~h}$ with mild agitation of $150 \mathrm{rpm}$, the decreases in solution absorbance was measured at $517 \mathrm{~nm}$ using a Cytation3 (Biotek) spectrophotometer. L-ascorbic acid (Sigma, Cat\# A4403-100MG) was used as a positive control. Absorbance of all samples without DPPH was subtracted to correct the background absorbance at $517 \mathrm{~nm}$. The DPPH radical scavenging activity $(\%)$ was calculated using the following formula: DPPH radical scavenging activity $(\%)=\left(A_{c}\right.$ $\left.-A_{s}\right) / A_{c} \times 100(\%)$, where $A_{c}$ is absorbance of control and $A_{s}$ is absorbance of samples.

\section{$\underline{\text { TAC assay (antioxidant activity assay) }}$}

The total antioxidant capacity (TAC) of SLS and TLS was confirmed by evaluating the free radical scavenging effect using the Oxiselect ${ }^{\mathrm{TM}}$ TAC assay kit (Cat\# STA-360, Cell Biolabs). Briefly, all reagents and a uric acid standard were prepared following the provided protocol. Samples were prepared with the reaction buffer and the copper ion solution and allowed to react at room temperature for $5 \mathrm{~min}$. After $5 \mathrm{~min}$, the quenching reagent was added and $100 \mu \mathrm{L}$ was then transferred to a 96-well plate. The uric acid standard curve was prepared following the provided protocol and $100 \mu \mathrm{L}$ was pipetted into the 96 -well plate. Absorbance at $490 \mathrm{~nm}$ was measured using a Cytation 3 (Biotek) spectrophotometer. Absorbance of all samples in the reaction buffer was subtracted to correct the background absorbance at $490 \mathrm{~nm}$. Using the linear regression from standard curve samples, uric acid equivalent (UAE)/mL for each sample was calculated.

\section{$\underline{\text { Cultures of patient-derived dermal fibroblasts }}$}

Skin tissue was collected from abdominoplasty patients who provided written informed consent as part of a protocol approved by the Institutional Review Board of Texas at Baylor College of Medicine (Approval \# H-38187) in accordance with the Declaration of Helsinki. A biobank of scar and matched normal uninjured skin tissue was obtained from abdominoplasty patients controlled for sex, age, ethnicity, surgery type, indication, wound site, and comorbidities. These skin tissues were grouped into low scarring (LS) and high scarring (HS) phenotypes based on the 
evaluation of their existing C-section scars using Vancouver Scar Scale (VSS). Skin obtained from patients with 1-3 score on VSS were categorized as LS phenotype (N). For each group, $n=3$ skin tissues were pooled. Only LS- and HS-normal (N) fibroblasts were used for cell studies and two donor cell lines were used for each hdFB phenotypes. Both LS-N and HS-N human dermal fibroblasts (dFBs) were maintained in DMEM (Cat\# 10567-014-500mL, Gibco) supplemented with 10\% fetal bovine serum (FBS, Cat\# 35-015-CV, Corning), Penicillin/Streptomycin (P/S, Cat\# 15140-122, Gibco), and antibiotic/antimycotic (anti/anti, Cat\#: 15240-062, Gibco). Only passages 8-10 were used for studies and cells were harvested at around 80\% confluency with TrypLE Express (Cat\#: 12604-021, Gibco) application and pelleted at $350 \mathrm{~g}$ for $5 \mathrm{~min}$. Supernatant was removed and hdFBs were gently resuspended in cell culture media and counted. Media was changed every other day.

Quantitative Reverse Transcriptase Polymerase Chain Reaction (qRT-PCR)

LS-N or HS-N hdFBs were seeded onto PEG-fGelMA-TLS composites at 50,000 cells $/ \mathrm{cm}^{2}$. Cell culture supernatants were collected from all of the gels and control wells at $24 \mathrm{~h}$ after culture initiation and stored in $-80^{\circ} \mathrm{C}$ with protease inhibitor cocktail (Sigma). At specified time points cell-seeded composites were removed and incubated with the application of TrypLE Express (Cat\#: 12604-021, Gibco) to generate a cell suspension. RNA was extracted following the suggested procedure from the PureLink RNA MicroPrep kit (Cat\#: 12183018A, ThermoFisher Scientific). Extracted RNA was evaluated for quantity and purity using a Take3 Micro-Volume plate (Biotek) and Cytation3 spectrophotometer (Biotek). cDNA was reverse-transcribed using a High-Capacity RNA-to-cDNA kit (Cat\#: 4387406, Applied Biosystems) following manufacturer's protocols. Primers for COL1A1, TGFB1 and GAPDH were purchased from Bio-Rad and those for ACTA2 (ASMA, FOR: 5' ACCCACAATGTCCCCATCTA 3', REV: 5' GAAGGAATAGCCACGCTCAG 3') and HIF1A (FOR: 5' GATGTAATGCTCCCCTCACC 3', REV: 5' CTTGATTGAGTGCAGGGTCA 3') were purchased from Millipore-Sigma. qRT-PCR was performed using Power 
SYBR Green PCR Master Mix (Cat\# 4367659, Applied Biosystem) in Bio-Rad CFX 384 RealTime system. Relative mRNA levels were calculated using the $2^{-\Delta \Delta C T}$ method and normalized to GAPDH. The gene expression in 2D cultures was normalized to one of the two cell line and that of 3D culture was normalized to PEG-fGelMA controls (without TLS).

\section{RESULTS}

$\underline{\text { Thiolation of lignosulfonate primarily functionalized aliphatic } \mathrm{OH}}$

The ${ }^{1} \mathrm{H}$ NMR spectroscopy of SLS and TLS (Figure S1, Supplementary Information) was used to confirm the thiolation of SLS (Figure 1a). The appearance of a broad peaks corresponding to the protons of the $-\mathrm{S}-\mathrm{CH}_{2}$ - group were centered between $\delta$ 1.9-3.2 ppm. Furthermore, chemical shifts for aliphatic-OH ( $\delta$ 2.8-4.3 ppm) were reduced when comparing SLS to TLS. To further quantitatively confirm the extent of thiolation with a higher degree of specificity, we performed ${ }^{31} \mathrm{P}$ NMR spectroscopy. ${ }^{47}$ Using ${ }^{31} \mathrm{P}$ NMR, the chemical shifts of phenolic-OH and aliphatic-OH were found as evidenced in Figure $1 \mathrm{~b}$. The chemical shifts at $\delta 132.2 \mathrm{ppm}$ was determined with the product of TMDP (2-chloro-4,4,5,5-tetramethyl-1,3,2-dioxaphospholane) hydrolysis and the lignin products as demonstrated in a previous report ${ }^{47}$ since the lignin products do not contain any phosphorous atom. The ${ }^{31} \mathrm{P}$ NMR spectra show peaks at 145.6-149.8 ppm (assigned to phenolic$\mathrm{OH}$ ) and at 144.4-137.6 ppm (assigned to aliphatic-OH) in Figure 1b. Quantitative analysis using the internal standard $(\mathrm{OH}$ group of cyclohexanol) peak at $145.0 \mathrm{ppm}$ with known concentration allowed us to determine the degree of thiolation, where the changes of the integrated peak intensity of phenolic-OH and aliphatic- $\mathrm{OH}$ before and after thiolation were 0.62 and 0.35 , respectively. These results further showed that aliphatic-OH groups were more actively involved in the incorporation of thiol than that of phenolic-OH groups, which would be advantageous to maintain antioxidant capacity of lignosulfonate. Using Ellman's assay, the incorporated thiol groups were quantified, confirming that the thiol concentration was precisely controlled by tuning reaction stoichi- 
ometry as evidenced by the thiol concentration of three different batches of TLS at different stoichiometric ratios of SLS to MPA (Figure 1c). When compared to the SLS control, concentrations of thiols were increased almost 20 -fold without compromising batch to batch replicability. In sum, TLS functionalization is tunable and primarily occurs at aliphatic $\mathrm{OH}$ groups.
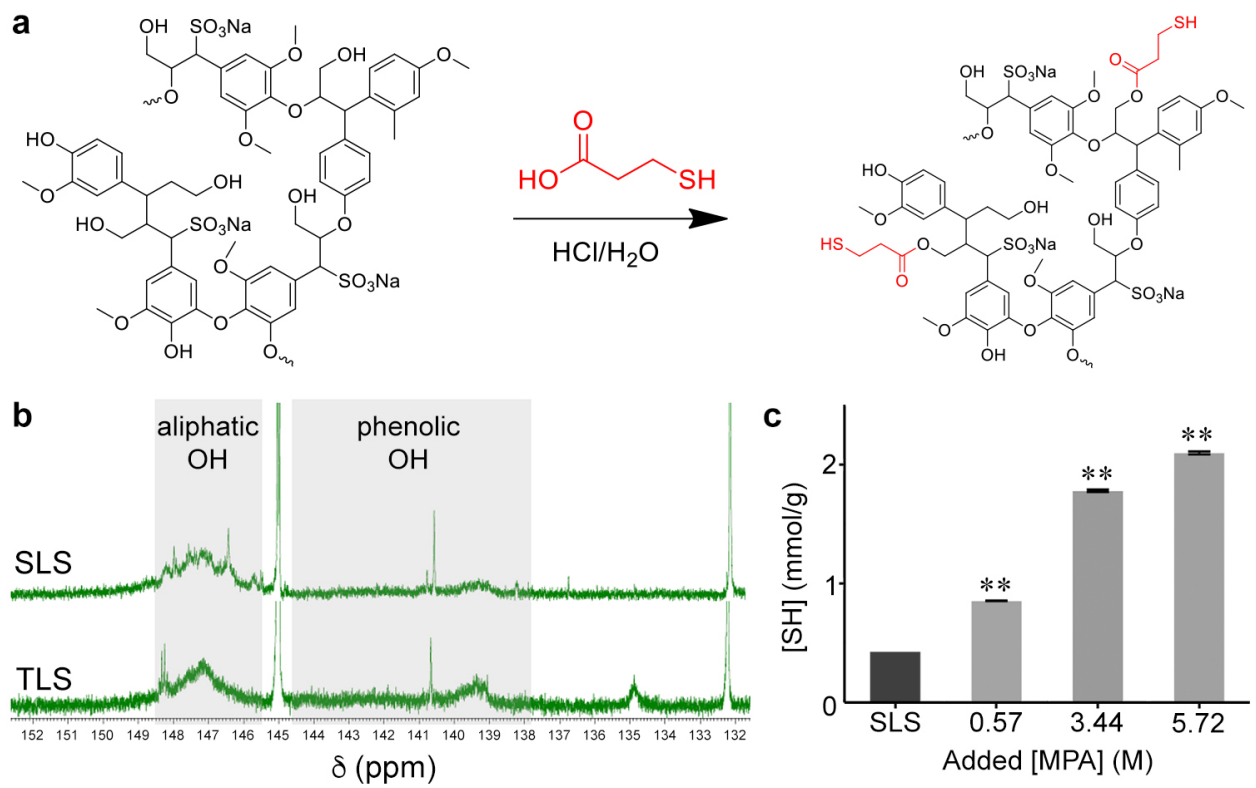

Figure 1. Schematic and assessment of SLS thiolation. (a) Thiolation of SLS to form TLS. (b) ${ }^{31} \mathrm{P}$ NMR (in $\mathrm{CDCl}_{3}$ ) spectra of SLS or TLS via TMDP (2-chloro-4,4,5,5-tetramethyl-1,3,2-dioxaphospholane) hydrolysis. (c) Thiol concentrations of TLS samples prepared under different stoichiometry determined by Ellman's assay. [MPA] is defined as the ratio of the mass of SLS to the number of moles of MPA; ${ }^{* *} p<0.01$, ANOVA Dunnett's post hoc test, mean \pm standard deviation (SD), $n=3$.

\section{Antioxidant capacity of SLS was not altered after thiolation}

To evaluate the antioxidant potential for SLS and TLS, we utilized two common assays to assess antioxidation using DPPH (2,2-diphenyl-1-picrylhydrazyl) and the reduction of copper (II) to copper (I). We tested the extent of DPPH inhibition by SLS and TLS at multiple concentrations from 1 to $5 \mathrm{mg} / \mathrm{mL}$. As shown in Figure 2a, TLS showed significantly higher DPPH inhibition in comparison to SLS and significantly lower DPPH inhibition in comparison to $L$-asc at all three concentrations. In Figure 2b, similar trends were observed, but the difference between SLS and TLS decreased. SLS also exhibited variability in the capacity of DPPH inhibition, which may be 
due to incomplete dissolution in the mixture of ethanol and water up to $30 \mathrm{~min}$ at higher concentrations (Figure 2a). However, the variability is disappeared after $24 \mathrm{~h}$ incubation, indicating that SLS is fully dissolved and radical scavenging groups are more available. In Figure 2c, TLS exhibited higher TAC (reducing $\mathrm{Cu}^{2+}$ to $\mathrm{Cu}^{+}$) than that of SLS at 1 and $2 \mathrm{mg} / \mathrm{mL}$. At 2 and $5 \mathrm{mg} / \mathrm{mL}$, TLS showed comparable TAC in comparison to $L$-asc. Apparently. TLS is a better scavenger than SLS since thiols can also scavenge radicals. As evidenced in Figure 1b, thiolation occurred mainly on aliphatic $\mathrm{OH}$. These results support that TLS possesses a dual mode of radical scavenging with phenolic groups of lignosulfonate and thiolated aliphatic chains of lignosulfonate.


Figure 2. Independent antioxidant assays to assess radical scavenging capacity of TLS. DPPH assay of SLS, TLS and L-ascorbic acid for (a) $30 \mathrm{~min}$ and (b) $24 \mathrm{~h}$. TAC assays with the same samples (c). * $\mathrm{p}<0.01$, ANOVA Dunnett's post hoc test, mean $\pm \mathrm{SD}, \mathrm{n}=3$.

\section{Methacrylation of fish gelatin yielded fGelMA with low viscosity at room temperature}

Methacrylation of fGelMA was assessed using ${ }^{1} \mathrm{H}$ NMR spectroscopy with $\mathrm{D}_{2} \mathrm{O}$ as a solvent (Figure S2, Supplementary Information) ${ }^{50-51}$. Pristine fGel shows the peak at $3.0 \mathrm{ppm}$ which is assigned to proton of primary amine in lysine. Upon the reaction with GMA, the intensity of the peak significantly decreased, indicating the disappearance of primary amine by the reaction. Simultaneously, the emergence of two peaks at 6.1-6.2 ppm and 5.7-5.8 ppm was observed, assigned to protons of alkene in the methacrylate. The degree of the lysine functionalization was calculated with integrated intensities of the peak of primary amine in lysine and the peak of phenylalanine at 7.2-7.5 ppm. The peak intensity of the phenylalanine was used as a reference to estimate the degree of functionalization by comparing the peak intensities of lysine amine before and after the 
reaction. In multiple performed reaction batches, the degree of functionalization was estimated at least $77 \%$. Using oscillating rheometry, we measured viscosity of fGelMA at 40 and $200 \mathrm{mg} / \mathrm{mL}$. As shown in Figure 3a, viscosities of fGel were $0.6 \mathrm{~Pa} \cdot \mathrm{s}(40 \mathrm{mg} / \mathrm{mL})$ and $3.2 \mathrm{~Pa} \cdot \mathrm{s}(200 \mathrm{mg} / \mathrm{mL})$, while those of fGelMA were $0.5 \mathrm{~Pa} \cdot \mathrm{s}(40 \mathrm{mg} / \mathrm{mL})$ and $1.14 \mathrm{~Pa} \cdot \mathrm{s}(200 \mathrm{mg} / \mathrm{mL})$ at room temperatures. Due to such low viscosity at room temperature, we were able to form composites including gelatin without adding acetic acid ${ }^{52}$ or heating ${ }^{53}$ in the cases of applying porcine gelatin. As shown in Figure S3 (Supplementary Information), the viscosity of porcine GeIMA (180 mg/mL) was several orders of magnitude higher than that of fGelMA (200 mg/mL). The reduced viscosity of fGelMA observed at high concentration of $200 \mathrm{mg} / \mathrm{mL}$ can be attributed to the removal of impurities in fGel by dialysis after methacrylation or by the reduction of the amount primary amine group which induces interchain interaction with carboxylic acid along the chains, instead of changes in chemical nature of gelatin chains

The addition of TLS improved stiffness and compensated the reduction of stiffness by adding $\underline{\text { fGelMA }}$

PEG composites were prepared at a 1:0.5 ene:thiol ratio, with a PEGDA concentration set at $40 \mathrm{mg} / \mathrm{mL}$. We attempted higher ene:thiol ratios, 1:1 for example, but had issues with crosslinking due to the ability of lignin to absorb UV light, which results in effective crosslinking of only the surface region. With the maximal antioxidant capacity from TLS and the interference by higher concentration of TLS ( $>5 \mathrm{mg} / \mathrm{mL}$ ) during photo-crosslinking of PEG composites ${ }^{54}$, we applied TLS at $5 \mathrm{mg} / \mathrm{mL}$ throughout our experiments.

To further delineate changes of mechanical properties upon incorporating TLS and/or fGelMA, we measured G' (storage modulus, elasticity) and G" (loss modulus, viscosity) under various conditions. Complete contact and certain axial force are required to measure viscoelasticity using a rheometer. However, we often observed that altering axial force can result in different $\mathrm{G}^{\prime}$ and $\mathrm{G}^{\prime \prime}$, thus we sought to extract a stress-strain curve from axial stress-compression data ${ }^{49}$. 
As shown in Figure $3 b$, all $\mathrm{G}^{\prime}$ were overlapped from around 0.3 to $0.5 \mathrm{kPa}$ and $\mathrm{G}^{\prime}$ and $\mathrm{G}^{\prime \prime}$ as a function of compression did not show significant difference at different compression varying from 0 to 0.2 (or $20 \%$ ). When these data were put in axial stress vs compression (Figure $3 \mathrm{~d}$ ), the slope yielded a modulus of elasticity and those values are summarized in Table 1. The incorporation of TLS increased the elasticity from 5.5 to $7.3 \mathrm{kPa}$ in the absence of fGelMA, while the incorporation of fGeIMA decreased without TLS decreased the elasticity from 5.5 to $2.6 \mathrm{kPa}$. Once we added 5 $\mathrm{mg} / \mathrm{mL}$ of TLS and $40 \mathrm{mg} / \mathrm{mL}$ of fGelMA to $40 \mathrm{mg} / \mathrm{mL}$ of PEG, the stiffness of the composite was increased to $4.2 \mathrm{kPa}$. This estimation is predictable, as evidenced by high $\mathrm{R}^{2}$ values, and the modulation of the stiffness of PEG composites is probably feasible by modulating the quantity of TLS and/or fGelMA incorporated. As shown in Figure 3c, loss tangent of all the PEG composites varied in such a narrow range from 0.06 , equivalent to 3.43 degree and indicative of covalently crosslinked, highly elastic hydrogels when subject to angular frequency from 0.628 to $19.9 \mathrm{rad} / \mathrm{s}$ at $2 \%$ strain. PEG exhibited highest loss tangent, while the incorporation of TLS conferred lowest loss tangent and minimal changes throughout the range of frequencies we tested (PEG-TLS). Incorporating fGelMA or fGelMA-TLS showed similar loss tangent and levels between those of PEG and TLS.

Table 1. Elastic modulus estimated by the slope of axial stress vs compression.

\begin{tabular}{cccc}
\hline & Slope (Elastic modulus, $\mathrm{kPa})$ & Intercept $(\mathrm{kPa})$ & $\mathrm{R}^{2}$ \\
\hline \hline PEG & 5.5 & 0.2 & 0.9422 \\
TLS (PEG-TLS) & 7.3 & 0.4 & 0.9512 \\
fGMA (PEG-fGelMA) & 2.6 & 0.4 & 0.9585 \\
fGMA-TLS (PEG-fGelMA-TLS) & 4.2 & 0.4 & 0.9760 \\
\hline
\end{tabular}



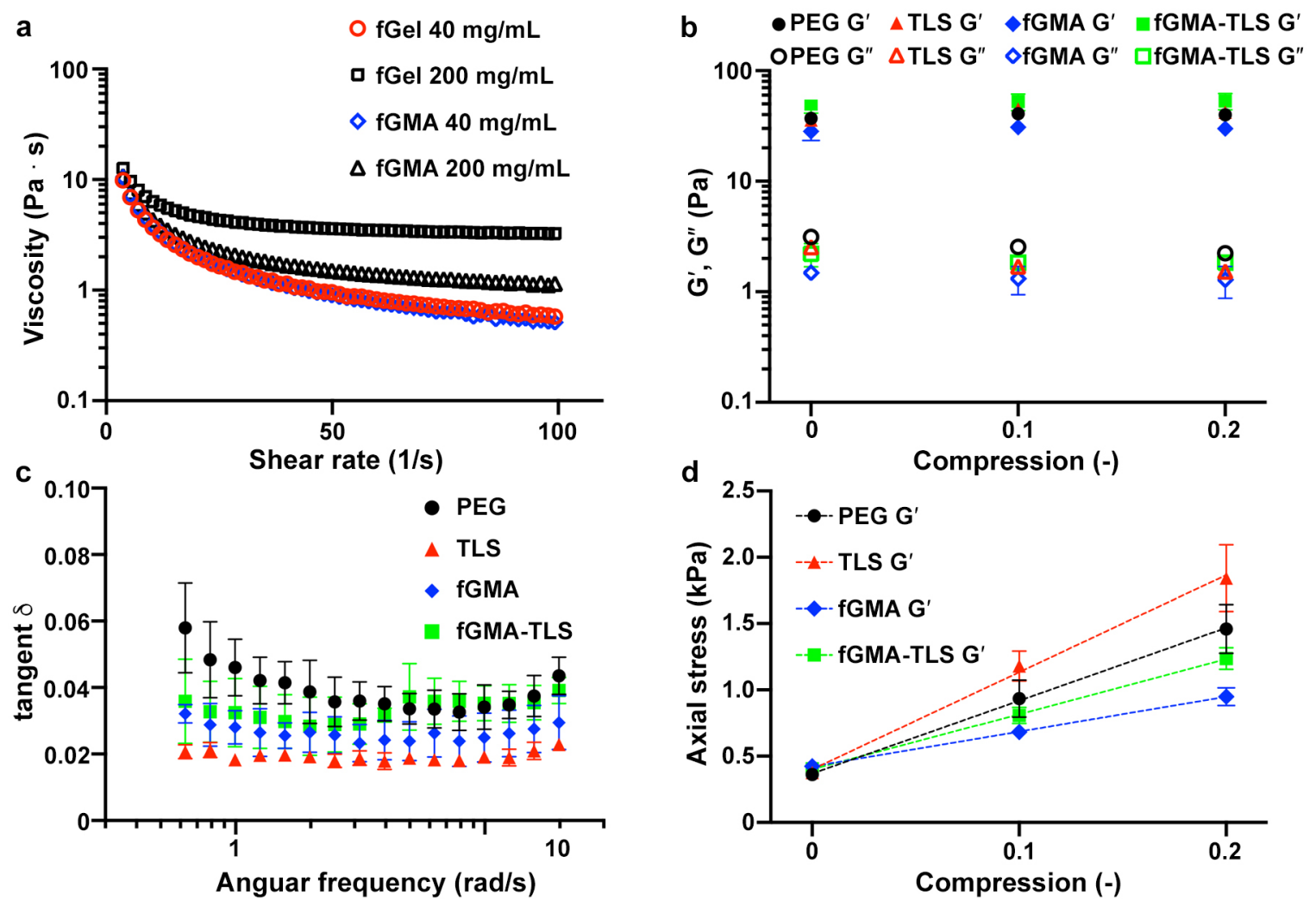

Figure 3. Assessment of rheological properties. (a) Viscosity of fGel (before methacrylation) and fGMA (fGelMA, after methacrylation) at 40 and $200 \mathrm{mg} / \mathrm{mL}$. (b) Storage ( $\mathrm{G}^{\prime}$ ) and loss (G") moduli of PEG (40 mg/mL), TLS (PEG $40 \mathrm{mg} / \mathrm{mL}$ and TLS $5 \mathrm{mg} / \mathrm{mL}$ ), fGMA (PEG $40 \mathrm{mg} / \mathrm{mL}$ and fGelMA $40 \mathrm{mg} / \mathrm{mL}, 4: 1(\mathrm{v} / \mathrm{v}))$ and fGMA-TLS (PEG $40 \mathrm{mg} / \mathrm{mL}$ and fGelMA $40 \mathrm{mg} / \mathrm{mL}(4: 1(\mathrm{v} / \mathrm{v})$ ) with TLS $5 \mathrm{mg} / \mathrm{mL}$ ) at compression varying from 0 to $20 \%$. All composites were crosslinked with $5 \mathrm{mg} / \mathrm{mL}$ LAP. (c) Loss tangent $(\delta)$ of the PEG composites from 0.62 to $19.9 \mathrm{rad} / \mathrm{s}$. (d) Axial stresses were plotted against compression varying from 0 to $20 \%$. Details of trend lines are summarized in Table 1. Mean $\pm S D, n=3$.

\section{$\underline{\text { fGelMA conferred attachment of hdFBs to PEG composites }}$}

fGelMA was added to the PEG-TLS precursor solutions and cast prior to UV crosslinking to synergistically enhance cell attachment of hdFBs. Stock solutions were prepared for PEG and fGelMA at 50 and $200 \mathrm{mg} / \mathrm{mL}$, respectively, and mixed at different volume ratios. The amount added was varied (Figure 4a-d) to introduce the minimal amount of fGelMA not to interrupt the antioxidation by TLS while maintaining the biophysical properties by PEG. As expected, PEGonly composites showed minimal cell attachment (Figure 4a). Increasing fGelMA further resulted in enhanced cell attachment with an 80:20 mixture exhibiting a hdFB monolayer across the surface of the composite (Figure 4c). While a 50:50 (Figure 4d) provided more binding sites for cell 
attachment, the distribution of hdFBs was less homogenous than that of the composite with 80:20 mixture.

PEG-fGelMA-TLS composites significantly altered the expression of fibrotic markers.

The goal of the current project was to test the antioxidant capacity of TLS in an engineered scaffold for tissue repair. Thus, we tested the alteration of fibrotic gene expression (COL1A1, ACTA2, TGFB1 and HIF1A) by the PEG-fGeIMA-TLS composites after $24 \mathrm{~h}$. As shown in Figure 4e, all the fibrotic markers showed that the expression of each marker from HS hdFB was significantly higher than that of LS hdFB. When hdFBs were maintained on PEG-fGelMA-TLS scaffolds, the difference between two different hdFB cell lines was largely reduced. The expression of TGFB1 in HS by PEG-fGelMA-TLS composites was significantly different from that of LS in normal tissue culture while the difference between LS and HS by PEG-fGelMA-TLS composites were not statistically significant. These results elucidate that PEG-fGelMA-TLS composites were able to remove the differential of hdFB responses associated with fibrosis over $24 \mathrm{~h}$, which could be beneficial to enhance the proliferation of HS hdFBs for regenerative medicine applications.
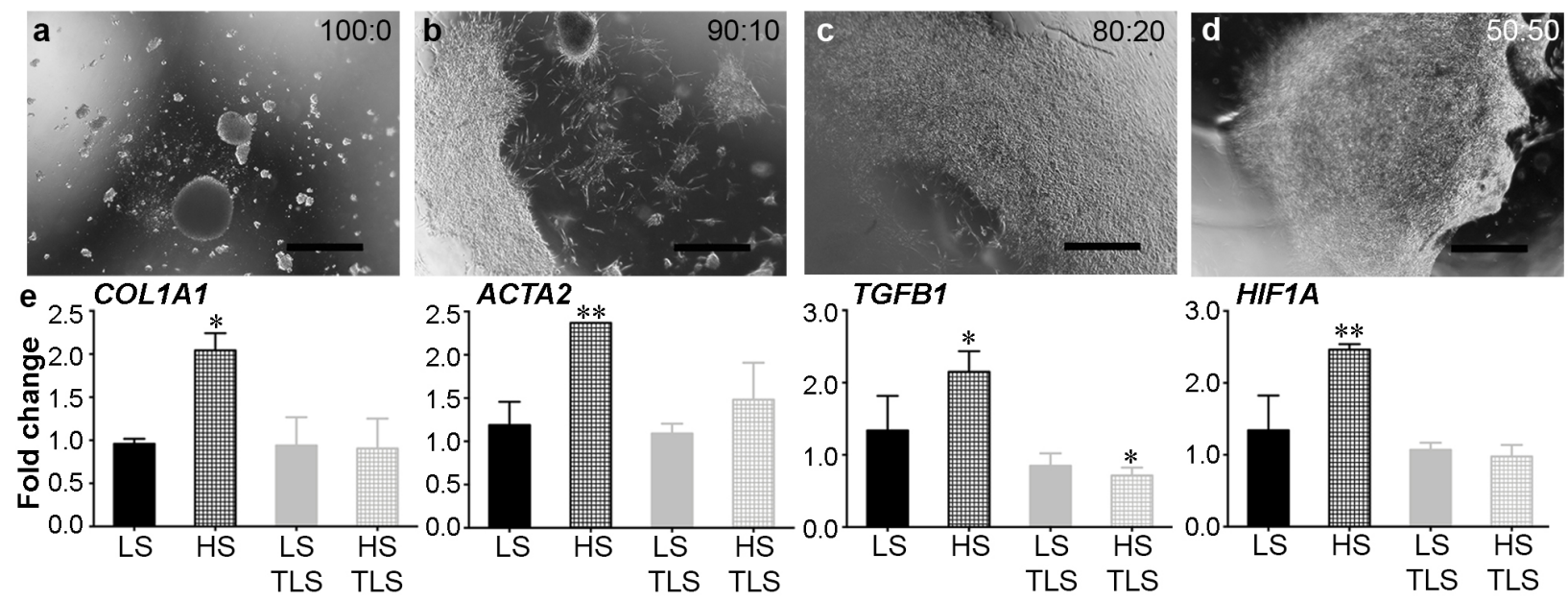

Figure 4. Attachment of hdFB to PEG composites and the modulation of fibrotic markers by TLS composites. Different ratios of PEG:fGelMA (v/v) composites (a) 100:0, (b) 90:10, (c) $80: 20$ and (d) 50:50, seeded with hdFBs for $48 \mathrm{~h}$. Scale bar, $1000 \mu \mathrm{m}$. (e) LS and HS hdFBs were maintained in normal 2D cultures, while TLS denotes LS and HS hdFBs were cultured on top of PEG-fGelMA-TLS composites. Each hdFB phenotype contains two different donor hdFB cell 
lines. LS or HS, $\mathrm{n}=2$, mean $\pm S \mathrm{~S}$; LS TLS or HS TLS, $\mathrm{n}=3$, mean $\pm S \mathrm{~S}$. ANOVA Dunnett's post hoc test, ${ }^{*} p<0.05$ and ${ }^{* *} p<0.01$.

\section{DISCUSSION}

The novel nature of our presented composite comes from the utilization of lignin. Lignin is produced as a waste byproduct from the pulping industry and has been underutilized given its high aromatic density ${ }^{55-56}$. Of several routes of integrating biomaterials into a scaffold, we used thiol-ene chemoselective chemistry ${ }^{39-40}$ to functionalize nanometer-sized SLS, which is extensively used for experimental simplicity with essentially no byproducts ${ }^{41-43}$. Our previous work showed that SLS contributed to stabilize mechanical properties of collagen type I matrix via physical mixing ${ }^{19}$. To further enhance stability of incorporated SLS in a matrix, we thiolated SLS targeting aliphatic $\mathrm{OH}$ for chemoselective crosslinking while preserving phenolic $\mathrm{OH}$ for its antioxidant capacity (Figure 1). Then, TLS was easily conjugated to acrylated PEG and fGelMA via thiolene click chemistry. The resulting composites provided a platform for presenting antioxidation without the concern for burst release that plagues current technologies such as nano- or microparticles or antioxidant solutions. There are numerous different methods and assays to evaluate the antioxidant capacity of different biomaterials. The antioxidant capacity of lignin has been extensively researched using different assays ${ }^{17}$, including DPPH, ABTS (2,2'-azinobis-(3ethylbenzthiazolin-6-sulfonic acid)), total phenolics content (TPC) and trolox equivalent antioxidant capacity $(T E A C)^{17-18}$. In our work we chose the DPPH and TAC assays as they evaluate antioxidant capacity in different ways and are widely used in literature. Using both assays, we confirmed the notion that TLS provides a dual mode of scavenging via preserved phenolic $\mathrm{OH}$ of lignosulfonate and thiol that was preferentially functionalized on aliphatic $\mathrm{OH}$ of lignosulfonate (Figure 2).

To confer cell attachment, we mixed fGelMA with PEG-TLS precursors. Compared to porcine GelMA ( $p$ GelMA), fGelMA was readily miscible in aqueous solutions without the need for 
additives or temperature changes. Previous literature combined PEG with pGeIMA but found significant phase separation due to immiscibility. The addition of acetic acid mitigated the phase separation issue $\mathrm{e}^{52}$ or heating to $40^{\circ} \mathrm{C}$ to prevent gelation ${ }^{57}$. As evidenced by viscosity measurement, no additives or heating is required to form PEG-fGelMA-TLS composites, otherwise which would adversely impact cellular functions by damaging cell membrane or cytoplasm. Our investigation supports the notion that TLS and fGelMA can be reliably integrated into widely used PEG hydrogels to test cell behavior.

To delineate the changes of stiffness by incorporating functional units, TLS for antioxidation and/or fGelMA for cell attachment, we plotted axial stress vs compression to extract stressstrain curves. This method was employed to assess rheological properties of colon cancer tissue $^{49}$. While oscillating rheometry is useful to evaluate rheological properties, assessing axial stress and the controlled gap between the top geometry and the bottom plate allowed us to evaluate the modulus of elasticity in a different way.

In addition to the antioxidant capacity of TLS, we were able to verify the attenuation of fibrotic markers (COL1A1, ACTA2, TGFB1 and HIF1A) by PEG-fGelMA-TLS composites (Figure $4 \mathrm{e}$ ), where the levels of these markers are indicative of the extent of fibrosis. As a major component in collagen type I, COL1A1 has been implicated in the overproduction of collagen and therefore increased fibrosis ${ }^{58}$. Furthermore, the comparison of fetal wounds (low scar formation) to adult wounds (high scar formation) shows an elevated ratio of collagen type I to type III for adults while fetal patients have the opposite ${ }^{59-60}$. Elevated ACTA expression is due to differentiated myofibroblasts which can be responsible for excess granulation tissues and fibrocontractive diseases. The differentiation of fibroblasts to myofibroblasts is due to mechanical stressed but is controlled by TGFB1 expression. During the wound healing process, both ACTA1 and ACTA2 act by contraction of the surrounding environment. Chronic or excessive contraction ultimately leads to deformation of the surrounding ECM network thus leading to further complications with the wound healing process or contracture, the permanent deformation of tissue ${ }^{61}$. Because the ACTA 
promoters contain a TGF $\beta 1$ receptor, elevated TGFB1 expression will lead to elevated expression of both ACTA1 and ACTA2 leading to either a reduced healing or malformed healing process ${ }^{62-}$ 63. The interaction of TGF $\beta 1$ with fibroblasts is critical for wound healing process, particularly during the proliferative phase ${ }^{61}$. Overexpression of TGFB1 ultimately leads to excess scar formation and reduced wound healing capacity. Additionally, adult wounds were found to contain higher expression of TGFB1 when compared to fetal wounds, low scarring pheotype ${ }^{64-66}$. HIF1 regulates cell apoptosis and adapts to aid in cellular survival. The particular subunit, HIF1A, is regulated by oxygen and therefore under normal conditions is readily degraded. With a wound site being under hypoxia the expression of HIF1A will steadily increase until remediated ${ }^{67}$. Furthermore, excessive buildup of HIF1A can also be found in patients with keloids and scleroderma tissues, when compared to the expression in normal skin ${ }^{68}$.

Several studies showed that the application of biomaterials in the absence of antioxidation resulted in significant increase in the fibrotic markers and tissue fibrosis. Injectable PEG-hyaluronic acid (HA) biomaterials encapsulated adipose-derived stromal cells and were subsequently delivered to a mouse model of diabetes (6-8 Week old Sprague Dawley) and showed significant increase of TGF $\beta 1$ at days 1 and 4 along with significantly higher levels of $\alpha$ SMA in hydrogel treated wounds after 21 days compared to the control ${ }^{69}$, while it is not clear if the PEG was responsible for the increase in TGF $\beta 1$ and $\alpha$ SMA or if it was the addition of HA to the composite or both. In another study fibroblasts were encapsulated in a PEG-block-poly( $L$-alanine) composites for enhanced wound healing applications ${ }^{70}$, which elevated the expression of COL1A1 and COL3A1, compared to Matrigel. When injected in vivo, the rate of wound closure was significantly increased with improved epithelialization and the formation of epidermis, hair follicles, and sebaceous glands compared to saline control. When porcine valvular interstitial cells were encapsulated in MMP-degradable PEG hydrogels, addition of TGF $\beta 1$ significantly increased the expression of ACTA2 and COL1A1 by day $2^{71}$. A PEG/gelatin composite with covalently bound elastin increased a 19-fold increase of COL1A1 but a significant reduction in the expression of ACTA2 
over 9 days in culture ${ }^{72}$. While the rate of expression is not directly comparable, these data indicate that the incorporation of TLS modulates the expression of COL1A1 and ACTA2 much faster than biomaterial composites without antioxidant capacity.

\section{CONCLUSIONS}

We sought to develop a precise and targeted method to formulate consistent composites. Thiol-ene click chemistry was utilized to synergistically form PEG-based TLS composites in an attempt to address the previous concerns over long-term stability. Thiolation of SLS was tailorable and resulted in an efficient method evaluated through NMR spectroscopy. When using two uniquely different assays to observe the antioxidant capacity or scavenging potential, TLS exhibited more scavenging potentials than SLS due to the preservation of phenolic component of SLS and thiolated aliphatic chains of SLS. Due to the anti-adhesion nature of PEG, we introduced fGelMA as a natural agent to enhance cell adhesion. Addition of fGelMA significantly increased cell adhesion of hdFBs with no phase separation of precursors. When cultured with hdFBs for 24h, PEG-fGeIMA-TLS composites were able to reduce the expression of key fibrotic genes in HS cells to that of LS cells. Consequently, the engineered PEG composites can be utilized as a cell culture platform utilizing lignosulfonate for enhance wound healing applications.

\section{AUTHOR CONTRIBUTIONS}

JPJ and MK conceived the experiments. JAB, DS, BJ, JC, and SAZ synthesized and prepared composites. AXB performed oscillating rheometry and ACG performed antioxidant assays. JAB, SAZ and UMP performed cell and molecular biology experiments. JAB, DS, SB, MK, and JPJ wrote the manuscript and all authors approved the final manuscript.

\section{ACKNOWLEDGMENTS}


The authors acknowledge the support from the National Science Foundation EPSCoR (Track 2 RII, OIA 1632854, JAB and JPJ). MK, DS, BK and JC acknowledge the support by the Basic Science Research Program through the National Research Foundation of Korea (NRF) funded by the Ministry of Education (2018R1D1A1B07044345). 


\section{REFERENCES}

1. Forman, H. J.; Torres, M., Reactive oxygen species and cell signaling: respiratory burst in macrophage signaling. Am J Respir Crit Care Med 2002, 166 (12 Pt 2), S4-8.

2. Scherz-Shouval, R.; Elazar, Z., Regulation of autophagy by ROS: physiology and pathology. Trends in Biochemical Sciences 2011, 36 (1), 30-38.

3. Finkel, T.; Holbrook, N. J., Oxidants, oxidative stress and the biology of ageing. Nature 2000, 408 (6809), 239-247.

4. $\quad$ Sauer, H.; Wartenberg, M.; Hescheler, J., Reactive Oxygen Species as Intracellular Messengers During Cell Growth and Differentiation. Cellular Physiology and Biochemistry 2001, 11 (4), 173-186.

5. Burdon, R. H., Superoxide and hydrogen peroxide in relation to mammalian cell proliferation. Free Radical Biology and Medicine 1995, 18 (4), 775-794.

6. Murrell, G. A. C.; Francis, M. J. O.; Bromley, L., Modulation of fibroblast proliferation by oxygen free radicals. Biochemical Journal 1990, 265 (3), 659-665.

7. Rao, G. N.; Berk, B. C., Active oxygen species stimulate vascular smooth muscle cell growth and proto-oncogene expression. Circulation Research 1992, 70 (3), 593-599.

8. Ruiz-Ginés, J. A.; López-Ongil, S.; González-Rubio, M.; González-Santiago, L.; Rodríguez-Puyol, M.; Rodríguez-Puyol, D., Reactive Oxygen Species Induce Proliferation of Bovine Aortic Endothelial Cells. Journal of Cardiovascular Pharmacology 2000, 35 (1), 109-113. 9. Wartenberg, M.; Diedershagen, H.; Hescheler, J.; Sauer, H., Growth stimulation versus induction of cell quiescence by hydrogen peroxide in prostate tumor spheroids is encoded by the duration of the $\mathrm{Ca}(2+)$ response. J Biol Chem 1999, 274 (39), 27759-67.

10. Del Bello, B.; Paolicchi, A.; Comporti, M.; Pompella, A.; Maellaro, E., Hydrogen peroxide produced during gamma-glutamyl transpeptidase activity is involved in prevention of apoptosis and maintenance of proliferation in U937 cells. Faseb J. 1999, 13 (1), 69-79.

11. Menon, S. G.; Sarsour, E. H.; Spitz, D. R.; Higashikubo, R.; Sturm, M.; Zhang, H.; Goswami, P. C., Redox Regulation of the $G<s u b>1</ s u b>$ to $S$ Phase Transition in the Mouse Embryo Fibroblast Cell Cycle. Cancer Research 2003, 63 (9), 2109-2117.

12. Mason, B. N.; Starchenko, A.; Williams, R. M.; Bonassar, L. J.; Reinhart-King, C. A., Tuning three-dimensional collagen matrix stiffness independently of collagen concentration modulates endothelial cell behavior. Acta Biomater 2013, 9 (1), 4635-44.

13. Preston, T. J.; Muller, W. J.; Singh, G., Scavenging of extracellular $\mathrm{H} 2 \mathrm{O} 2$ by catalase inhibits the proliferation of HER-2/Neu-transformed rat-1 fibroblasts through the induction of a stress response. J Biol Chem 2001, 276 (12), 9558-64.

14. Zhao, C.; Xie, S.; Pu, Y.; Zhang, R.; Huang, F.; Ragauskas, A. J.; Yuan, J. S., Synergistic enzymatic and microbial lignin conversion. Green Chem. 2016, 18 (5), 1306-1312.

15. Pan, X.; Kadla, J. F.; Ehara, K.; Gilkes, N.; Saddler, J. N., Organosolv ethanol lignin from hybrid poplar as a radical scavenger: Relationship between lignin structure, extraction conditions, and antioxidant activity. J. Agric. Food Chem. 2006, 54, 5806-5813.

16. Stewart, D., Lignin as a base material for materials applications: Chemistry, application and economics. Ind. Crop. Prod. 2008, 27 (2), 202-207.

17. Dizhbite, T.; Telysheva, G.; Jurkjane, V.; Viesturs, U., Characterization of the radical scavenging activity of lignins--natural antioxidants. Bioresour Technol 2004, 95 (3), 309-17.

18. Baba, S. A.; Malik, S. A., Determination of total phenolic and flavonoid content, antimicrobial and antioxidant activity of a root extract of Arisaema jacquemontii Blume. Journal of Taibah University for Science 2015, 9 (4), 449-454.

19. Belgodere, J. A.; Zamin, S. A.; Kalinoski, R. M.; Astete, C. E.; Penrod, J. C.; Hamel, K. M.; Lynn, B. C.; Rudra, J. S.; Shi, J.; Jung, J. P., Modulating Mechanical Properties of Collagen-Lignin Composites. ACS Applied Bio Materials 2019, 2 (8), 3562-3572. 
20. Quraishi, S.; Martins, M.; Barros, A. A.; Gurikov, P.; Raman, S. P.; Smirnova, I.; Duarte, A. R. C.; Reis, R. L., Novel non-cytotoxic alginate-lignin hybrid aerogels as scaffolds for tissue engineering. The Journal of Supercritical Fluids 2015, 105, 1-8.

21. Yang, W.; Fortunati, E.; Bertoglio, F.; Owczarek, J. S.; Bruni, G.; Kozanecki, M.; Kenny, J. M.; Torre, L.; Visai, L.; Puglia, D., Polyvinyl alcohol/chitosan hydrogels with enhanced antioxidant and antibacterial properties induced by lignin nanoparticles. Carbohydrate Polymers 2018, 181, 275-284.

22. Witzler, M.; Alzagameem, A.; Bergs, M.; Khaldi-Hansen, B. E.; Klein, S. E.; Hielscher, D.; Kamm, B.; Kreyenschmidt, J.; Tobiasch, E.; Schulze, M., Lignin-Derived Biomaterials for Drug Release and Tissue Engineering. Molecules 2018, 23 (8), 1885.

23. Kai, D.; Zhang, K.; Jiang, L.; Wong, H. Z.; Li, Z.; Zhang, Z.; Loh, X. J., Sustainable and Antioxidant Lignin-Polyester Copolymers and Nanofibers for Potential Healthcare Applications. ACS Sustainable Chemistry \& Engineering 2017, 5 (7), 6016-6025.

24. Kai, D.; Ren, W.; Tian, L.; Chee, P. L.; Liu, Y.; Ramakrishna, S.; Loh, X. J., Engineering Poly(Lactide)-Lignin Nanofibers with Antioxidant Activity for Biomedical Application. ACS Sustainable Chem. Eng. 2016, 4 (10), 5268.

25. Sghayyar, H. N. M.; Lim, S. S.; Ahmed, I.; Lai, J. Y.; Cheong, X. Y.; Chong, Z. W.; Lim, A. F. X.; Loh, H.-S., Fish biowaste gelatin coated phosphate-glass fibres for wound-healing application. European Polymer Journal 2020, 122.

26. Zhou, L.; Xu, T.; Yan, J.; Li, X.; Xie, Y.; Chen, H., Fabrication and characterization of matrine-loaded konjac glucomannan/fish gelatin composite hydrogel as antimicrobial wound dressing. Food Hydrocolloids 2020, 104.

27. Zhang, X.; Kim, G. J.; Kang, M. G.; Lee, J. K.; Seo, J. W.; Do, J. T.; Hong, K.; Cha, J. M.; Shin, S. R.; Bae, H., Marine Biomaterial-Based Bioinks for Generating 3D Printed Tissue Constructs. Mar Drugs 2018, 16 (12).

28. Yoon, H. J.; Shin, S. R.; Cha, J. M.; Lee, S.-H.; Kim, J.-H.; Do, J. T.; Song, H.; Bae, H., Cold Water Fish Gelatin Methacryloyl Hydrogel for Tissue Engineering Application. PLOS ONE 2016, 11 (10), e0163902.

29. Gómez-Guillén, M. C.; Pérez-Mateos, M.; Gómez-Estaca, J.; López-Caballero, E.; Giménez, B.; Montero, P., Fish gelatin: a renewable material for developing active biodegradable films. Trends in Food Science \& Technology 2009, 20 (1), 3-16.

30. Chiou, B.-S.; Avena-Bustillos, R. J.; Bechtel, P. J.; Jafri, H.; Narayan, R.; Imam, S. H.; Glenn, G. M.; Orts, W. J., Cold water fish gelatin films: Effects of cross-linking on thermal, mechanical, barrier, and biodegradation properties. European Polymer Journal 2008, 44 (11), 3748-3753.

31. Chiou, B.-S.; Avena-Bustillos, R. J.; Shey, J.; Yee, E.; Bechtel, P. J.; Imam, S. H.; Glenn, G. M.; Orts, W. J., Rheological and mechanical properties of cross-linked fish gelatins. Polymer 2006, 47 (18), 6379-6386.

32. Songchotikunpan, P.; Tattiyakul, J.; Supaphol, P., Extraction and electrospinning of gelatin from fish skin. International Journal of Biological Macromolecules 2008, 42 (3), 247-255.

33. An, K.; Liu, H.; Guo, S.; Kumar, D. N. T.; Wang, Q., Preparation of fish gelatin and fish gelatin/poly(l-lactide) nanofibers by electrospinning. International Journal of Biological Macromolecules 2010, 47 (3), 380-388.

34. Sow, L. C.; Peh, Y. R.; Pekerti, B. N.; Fu, C.; Bansal, N.; Yang, H., Nanostructural analysis and textural modification of tilapia fish gelatin affected by gellan and calcium chloride addition. LWT - Food Science and Technology 2017, 85, 137-145.

35. Zhu, S.; Yuan, Q.; Yin, T.; You, J.; Gu, Z.; Xiong, S.; Hu, Y., Self-assembly of collagenbased biomaterials: preparation, characterizations and biomedical applications. Journal of Materials Chemistry B 2018, 6 (18), 2650-2676.

36. Lv, L.-C.; Huang, Q.-Y.; Ding, W.; Xiao, X.-H.; Zhang, H.-Y.; Xiong, L.-X., Fish gelatin: The novel potential applications. Journal of Functional Foods 2019, 63. 
37. Tian, J.; Wang, Y.; Li, J.; Chen, Y.; Qinchen, J.; Deng, F.; Wu, X.; Liu, R.; Xiong, S.; Rong, J.; Hu, Y., Structural characteristics and physicochemical properties of fresh-water fish gelatins with different molecular weights and their potential application to food capsule film fabrication. Materials Express 2020, 10 (3), 419-429.

38. Vandooren, J.; Van den Steen, P. E.; Opdenakker, G., Biochemistry and molecular biology of gelatinase B or matrix metalloproteinase-9 (MMP-9): The next decade. Critical Reviews in Biochemistry and Molecular Biology 2013, 48 (3), 222-272.

39. Liu, H. L.; Chung, H. Y., Self-Healing Properties of Lignin-Containing Nanocomposite: Synthesis of Lignin-Graft-Poly(5-Acetylaminopentyl Acrylate) Via Raft and Click Chemistry. Macromolecules 2016, 49 (19), 7246.

40. Han, Y. M.; Yuan, L.; Li, G. Y.; Huang, L. H.; Qin, T. F.; Chu, F. X.; Tang, C. B., Renewable Polymers from Lignin Via Copper-Free Thermal Click Chemistry. Polymer 2016, 83, 92.

41. Kolb, H. C.; Sharpless, K. B.; Finn, M. G., Click Chemistry: Diverse Chemical Function from a Few Good Reactions. Angew. Chem., Int. Ed. 2001, 40 (11), 2004.

42. Hoyle, C. E.; Bowman, C. N., Thiol-Ene Click Chemistry. Angew. Chem., Int. Ed. 2010, 49 (9), 1540.

43. Lowe, A. B., Thiol-Ene "Click" Reactions and Recent Applications in Polymer and Materials Synthesis: A First Update. Polym. Chem. 2014, 5 (17), 4820.

44. Liu, H.; Chung, H., Visible-Light Induced Thiol-Ene Reaction on Natural Lignin. ACS Sustainable Chemistry \& Engineering 2017, 5 (10), 9160-9168.

45. Jacob, C., A Scent of Therapy: Pharmacological Implications of Natural Products Containing Redox-Active Sulfur Atoms. Nat. Prod. Rep. 2006, 23 (6), 851.

46. Wang, Z.; Tian, Z.; Menard, F.; Kim, K., Comparative study of gelatin methacrylate hydrogels from different sources for biofabrication applications. Biofabrication 2017, 9 (4), 044101.

47. Liu, L. Y.; Hua, Q.; Renneckar, S., A simple route to synthesize esterified lignin derivatives. Green Chem. 2019, 21 (13), 3682-3692.

48. Jin, C.; Zhang, X.; Xin, J.; Liu, G.; Wu, G.; Kong, Z.; Zhang, J., Clickable synthesis of 1,2,4-triazole modified lignin-based adsorbent for the selective removal of $\mathrm{Cd}(\mathrm{II})$. ACS Sustain. Chem. Eng. 2017, 5 (5), 4086-4093.

49. Deptuła, P.; Łysik, D.; Pogoda, K.; Cieśluk, M.; Namiot, A.; Mystkowska, J.; Król, G.; Głuszek, S.; Janmey, P. A.; Bucki, R., Tissue Rheology as a Possible Complementary Procedure to Advance Histological Diagnosis of Colon Cancer. ACS Biomater Sci Eng 2020, 6 (10), 5620-5631.

50. Hoch, E.; Schuh, C.; Hirth, T.; Tovar, G. E.; Borchers, K., Stiff gelatin hydrogels can be photo-chemically synthesized from low viscous gelatin solutions using molecularly functionalized gelatin with a high degree of methacrylation. J Mater Sci Mater Med 2012, 23 (11), 2607-17.

51. Nguyen, A. H.; McKinney, J.; Miller, T.; Bongiorno, T.; McDevitt, T. C., Gelatin methacrylate microspheres for controlled growth factor release. Acta Biomaterialia 2015, 13, 101-110.

52. Liang, J.; Guo, Z.; Timmerman, A.; Grijpma, D.; Poot, A., Enhanced mechanical and cell adhesive properties of photo-crosslinked PEG hydrogels by incorporation of gelatin in the networks. Biomed Mater 2019, 14 (2), 024102.

53. Hutson, C. B.; Nichol, J. W.; Aubin, H.; Bae, H.; Yamanlar, S.; Al-Haque, S.; Koshy, S. T.; Khademhosseini, A., Synthesis and characterization of tunable poly(ethylene glycol): gelatin methacrylate composite hydrogels. Tissue Eng Part A 2011, 17 (13-14), 1713-23. 
54. Dean, J. C.; Navotnaya, P.; Parobek, A. P.; Clayton, R. M.; Zwier, T. S., Ultraviolet spectroscopy of fundamental lignin subunits: guaiacol, 4-methylguaiacol, syringol, and 4methylsyringol. J Chem Phys 2013, 139 (14), 144313.

55. $\quad \mathrm{Hu}, \mathrm{T} . \mathrm{Q}$., Chemical Modification, Properties, and Usage of Lignin. Springer US: 2002; Vol. 1, p 291.

56. Laurichesse, S.; Avérous, L., Chemical modification of lignins: Towards biobased polymers. Progress in Polymer Science \$V 39 2014, (7), 1266-1290.

57. Kim, P.; Yuan, A.; Nam, K. H.; Jiao, A.; Kim, D. H., Fabrication of poly(ethylene glycol): gelatin methacrylate composite nanostructures with tunable stiffness and degradation for vascular tissue engineering. Biofabrication 2014, 6 (2), 024112.

58. Ma, H. P.; Chang, H. L.; Bamodu, O. A.; Yadav, V. K.; Huang, T. Y.; Wu, A. T. H.; Yeh, C. T.; Tsai, S. H.; Lee, W. H., Collagen 1A1 (COL1A1) Is a Reliable Biomarker and Putative Therapeutic Target for Hepatocellular Carcinogenesis and Metastasis. Cancers (Basel) 2019, $11(6)$.

59. Gurtner, G. C.; Werner, S.; Barrandon, Y.; Longaker, M. T., Wound repair and regeneration. Nature 2008, 453 (7193), 314-321.

60. McPherson, J. M.; Ledger, P. W.; Ksander, G.; Sawamura, S. J.; Conti, A.; Kincaid, S.; Michaeli, D.; Clark, R. A. F., The Influence of Heparin on the Wound Healing Response to Collagen Implants in vivo. Collagen and Related Research 1988, 8 (1), 83-100.

61. Tomasek, J. J.; Gabbiani, G.; Hinz, B.; Chaponnier, C.; Brown, R. A., Myofibroblasts and mechano-regulation of connective tissue remodelling. Nat Rev Mol Cell Biol 2002, 3 (5), 349-63.

62. Hautmann, M. B.; Madsen, C. S.; Owens, G. K., A transforming growth factor beta (TGFbeta) control element drives TGFbeta-induced stimulation of smooth muscle alpha-actin gene expression in concert with two CArG elements. J Biol Chem 1997, 272 (16), 10948-56. 63. Roy, S. G.; Nozaki, Y.; Phan, S. H., Regulation of alpha-smooth muscle actin gene expression in myofibroblast differentiation from rat lung fibroblasts. Int J Biochem Cell Biol 2001, 33 (7), 723-34.

64. Burrington, J. D., Wound healing in the fetal lamb. Journal of Pediatric Surgery 1971, 6 (5), 523-528.

65. Rowlatt, U., Intrauterine wound healing in a 20 week human fetus. Virchows Archiv $A$ 1979, 381 (3), 353-361.

66. Sen, C. K.; Gordillo, G. M.; Roy, S.; Kirsner, R.; Lambert, L.; Hunt, T. K.; Gottrup, F.; Gurtner, G. C.; Longaker, M. T., Human skin wounds: A major and snowballing threat to public health and the economy. Wound Repair and Regeneration 2009, 17 (6), 763-771.

67. Semenza, G. L., Regulation of metabolism by hypoxia-inducible factor 1. Cold Spring Harb Symp Quant Biol 2011, 76, 347-53.

68. Distler, J. H.; Jungel, A.; Pileckyte, M.; Zwerina, J.; Michel, B. A.; Gay, R. E.; KowalBielecka, O.; Matucci-Cerinic, M.; Schett, G.; Marti, H. H.; Gay, S.; Distler, O., Hypoxia-induced increase in the production of extracellular matrix proteins in systemic sclerosis. Arthritis Rheum 2007, 56 (12), 4203-15.

69. Xu, Q.; A, S.; Gao, Y.; Guo, L.; Creagh-Flynn, J.; Zhou, D.; Greiser, U.; Dong, Y.; Wang, F.; Tai, H.; Liu, W.; Wang, W.; Wang, W., A hybrid injectable hydrogel from hyperbranched PEG macromer as a stem cell delivery and retention platform for diabetic wound healing. Acta Biomater 2018, 75, 63-74.

70. Yun, E. J.; Yon, B.; Joo, M. K.; Jeong, B., Cell therapy for skin wound using fibroblast encapsulated poly(ethylene glycol)-poly(L-alanine) thermogel. Biomacromolecules 2012, 13 (4), 1106-11.

71. Benton, J. A.; Fairbanks, B. D.; Anseth, K. S., Characterization of valvular interstitial cell function in three dimensional matrix metalloproteinase degradable PEG hydrogels. Biomaterials 2009, 30 (34), 6593-603. 
72. Cao, Y.; Lee, B. H.; Irvine, S. A.; Wong, Y. S.; Bianco Peled, H.; Venkatraman, S., Inclusion of Cross-Linked Elastin in Gelatin/PEG Hydrogels Favourably Influences Fibroblast Phenotype. Polymers (Basel) 2020, 12 (3). 


\section{SUPPLEMENTARY METHODS}

\section{Synthesis of methacrylated porcine gelatin (pGelMA)}

In a scintillation vial, $1.0 \mathrm{~g}$ of porcine skin gelatin (Type A, MP Biomedicals, Cat\#901771) is dissolved in $10 \mathrm{~mL}$ Phosphate Buffer Saline (PBS) at $50^{\circ} \mathrm{C}$. Additional $0.1782 \mathrm{~g}$ of 1-Ethyl-3(3-dimethylaminopropyl) carbodiimide (EDC, TCI, Cat\#D1601), $0.1070 \mathrm{~g}$ of N-Hydroxysuccinimide (NHS, TCl, Cat\#H0623) were dissolved in $2.0 \mathrm{~mL}$ of dimethyl sulfoxide (DMSO, MP Biomedicals, Cat\#196055). Next, $0.1 \mathrm{~mL}$ of methacrylic acid (MA, Acros Organics, Cat\#1683-2500) was added, dropwise, to the DMSO solution, a stir bar was added, and placed into an oil bath at $40^{\circ} \mathrm{C}$ for $30 \mathrm{~min}$. After $30 \mathrm{~min}$, MA solution was added, dropwise, to the gelatin solution with a stir bar. The GeIMA solution was placed into the oil bath at $50^{\circ} \mathrm{C}$ for $1.5 \mathrm{~h}$. This reaction introduces methacryloyl substitution on the amine of the amino acid residues of gelatin. Once the reaction was completed, GelMA was placed into dialysis tubing (Spectra/Por 1 Dialysis Membrane, 6-8 kDa, Cat\#132655T), then placed into a beaker with Milli-Q water (>18.2 $\Omega \cdot \mathrm{cm})$, and then onto a hot plate at $40^{\circ} \mathrm{C}$ for 1 week. Water was exchanged twice a day for the entire duration. Dialysis allowed for the complete removal of the low-molecular-weight impurities (including unreacted MA and MA byproducts and DMSO), which are potentially cytotoxic. Finally, the dialyzed solution was lyophilized (Freezone Model 77530, Labconco) for 3 days and stored at $4^{\circ} \mathrm{C}$ until use. The degree of substitution was calculated using ${ }^{1} \mathrm{H}$ nuclear magnetic resonance (NMR), yielding about $87 \%$. 


\section{SUPPLEMENTARY FIGURES}

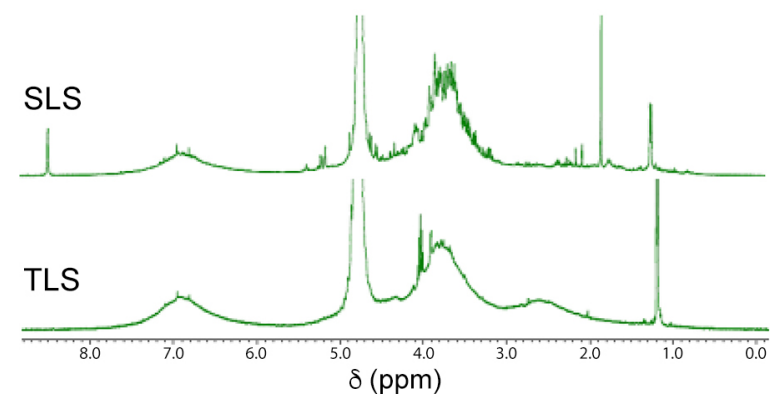

Figure S1. ${ }^{1} \mathrm{H}$ NMR spectra of SLS and TLS. ${ }^{1} \mathrm{H}$ NMR spectra were normalized with the peak of $\delta$ 5.6-8.2 ppm, which is for aromatic proton. In comparison with the SLS, ${ }^{1} \mathrm{H}$ NMR spectrum of TLS roughly confirmed the functionalization by the appearance of a broad peaks that corresponded to protons of $\mathrm{CH}_{2}$ groups adjacent to thiol ( $\delta$ 1.9-3.2 ppm). The chemical shifts for protons in aliphatic groups ( $\delta 2.8-4.3 \mathrm{ppm}$ ) reduced after the functionalization.

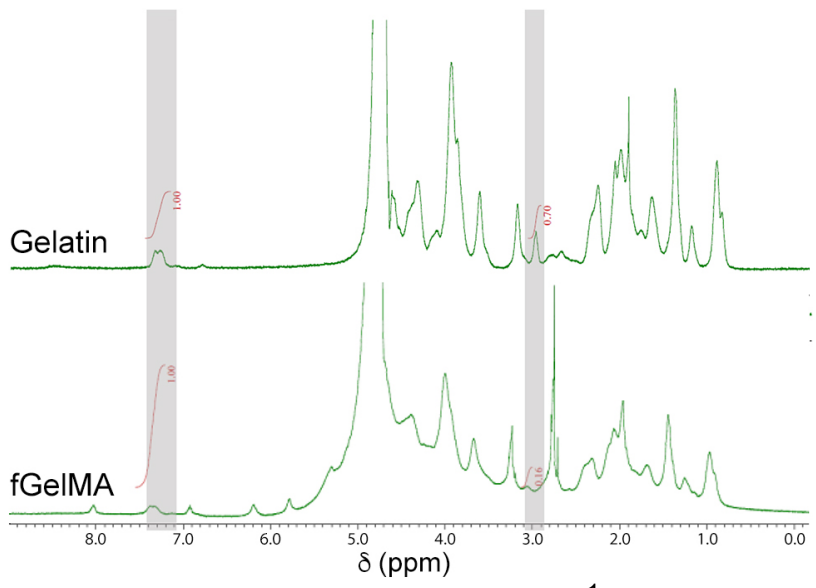

Figure S2. Assessment of the methacrylation of fGel. ${ }^{1} \mathrm{H}$ NMR spectra of pristine fGel and fGelMA in $\mathrm{D}_{2} \mathrm{O}$. The incorporation of methacrylate was confirmed by the decrease in the signal from the primary amine of lysine and the emergence of the signal from alkene in the methacrylate.

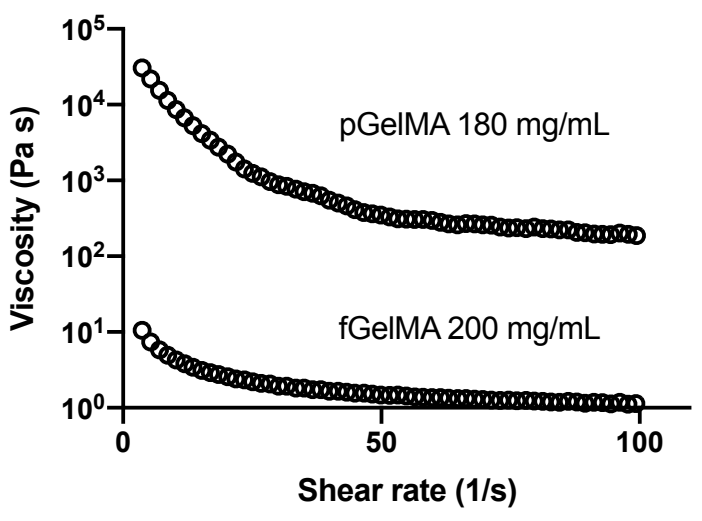

Figure S3. Comparison of viscosity of fGelMA to that of pGelMA. The viscosity of pGelMA at $180 \mathrm{mg} / \mathrm{mL}$ and fGelMA at $200 \mathrm{mg} / \mathrm{mL}$ was measured by oscillating rheometry. pGelMA at 180 $\mathrm{mg} / \mathrm{mL}$ is the highest concentration that can be prepared in liquid. 